\title{
IMAGINARY AUDIENCE, PERSONAL FABLE, DAN PERILAKU AGRESI REMAJA
}

\section{Salma Muthia Azhari, Tina Hayati Dahlan, M. Ariez Mustofa}

Departemen Psikologi, Fakultas Ilmu Pendidikan, Universitas Pendidikan Indonesia Email: salmamuthiaa@student.upi.edu,tinadahlan_psi@upi.edu,ariezmusthofa@yahoo.com

\begin{abstract}
This study aimed to identify the predictions of imaginary audience and personal fable to the aggression behavior of adolescents in the city of Bandung. Participants of the study were 395 adolescents that range 13-18 years old, selected by cluster random sampling techniques. The research data was collected by the New Imaginary Audience Scale (NIAS), the New Personal Fable Scale (NPFS), and the Buss-Perry Aggression Questionnaire that had been adapted into Indonesian. Processing data research using simple and multiple linear regression analysis. The results of this study indicate that there was significantly effect of imaginary audience and personal fable on agression behavior. Simultaneously the contribution of imaginary audience and personal fable to adolescent aggression behavior in Bandung is $12 \%$. The contribution of imaginary audience to adolescent aggression behavior is partially higher than personal fable contribution.
\end{abstract}

Key words: imaginary audience, personal fable, aggression behavior

\begin{abstract}
Abstrak
Penelitian ini bertujuan untuk mengidentifikasi kontribusi imaginary audience dan personal fable terhadap perilaku agresi remaja. Responden pada penelitian ini berjumlah 395 orang yang merupakan remaja berusia 13-18 tahun yang dipilih dengan menggunakan teknik cluster random sampling. Pengambilan data penelitian ini menggunakan instrument New Imaginary Audience Scale (NIAS), New Personal Fable Scale (NPFS), dan Buss-Perry Aggression Questionnaire yang sudah diadaptasi ke dalam Bahasa Indonesia. Pengolahan data penelitian menggunakan analisis regresi linear sederhana dan berganda. Hasil penelitian ini menunjukkan terdapat pengaruh yang signifikan imaginary audience dan personal fable terhadap perilaku agresi. Secara simultan kontribusi imaginary audience dan personal fable terhadap perilaku agresi remaja sebesar $12 \%$. Kontribusi imaginary audience terhadap perilaku agresi remaja secara parsial lebih tinggi dibandingkan kontribusi personal fable.
\end{abstract}

Kata kunci: imaginary audience; personal fable; perilaku agresi

\section{PENDAHULUAN}

Remaja merupakan masa transisi dari anak-anak menjadi dewasa (Batubara, 2010). Pada masa ini, remaja merasakan banyak sekali perubahan, seperti hormonal, fisik, psikologis, sosial, dan kognitif (Batubara, 2010). Masa remaja juga merupakan waktu di mana seorang individu sedang mencari jati diri yang mendorongnya untuk memiliki 
keingintahuan yang besar, ingin tampil menonjol agar eksistensi atau keberadaannya diakui orang lain (Pratiwi dan Basuki, 2011). Salah satu cara remaja agar keberadaannya diakui adalah dengan cara mencari sensasi, mencari pengalaman baru, bersedia mengambil resiko, mencoba hal-hal baru yang menantang, dan memiliki kreativitas yang tinggi (Astuti, 2010; Saudi, Hartini \& Bahar 2018).

Masa remaja sebagai salah satu tahap perkembangan kehidupan yang akan dilewati oleh setiap individu merupakan masa yang cukup sulit, karena pada masa ini akan terjadi differentiation failure atau ketidakmampuan remaja dalam membedakan apa yang menjadi keyakinan dirinya dan orang lain, misalnya seorang remaja meyakini bahwa orang lain selalu memperhatikan dirinya, padahal kenyataannya tidak (Piaget \& Inhelder, 1956). Selain itu, pada masa ini juga para remaja sedang mengalami fase storm and stress serta masa pencarian identitas (Santrock, 2011).

Pencarian identitas yang dilakukan oleh remaja merupakan salah satu kebutuhan yang harus dipenuhi oleh dirinya karena melalui pencarian identitaslah remaja dapat mengetahui siapa mereka sebenarnya. Remaja yang berada pada tahapan pencarian identitas ini memiliki energi yang besar dan berlebih sehingga menyebabkan mereka terus mencoba hal yang dianggap baru (Setiawati, 2015). Jika energi tersebut tidak disalurkan pada halhal yang positif, seringkali remaja menyalurkan kelebihan energinya pada hal yang negatif, contohnya perilaku agresi (Setiawati, 2015).

Perilaku agresi merupakan suatu dorongan atau keinginan untuk menyakiti orang lain dengan cara mengekspresikan perasaan negatif yang dimilikinya untuk mencapai tujuan yang ia miliki (Buss \& Perry, 1992). Terdapat enam jenis perilaku agresi, yaitu perilaku agresi secara terang-terangan, perilaku agresi instrumental, perilaku agresi positif (assertiveness), perilaku agresi negatif (violence), perilaku agresi tidak langsung, dan perilaku agresi langsung (Feshbach, 1969). Namun berdasarkan penelitian Santana dan Kumala (2017) perilaku agresi negatif lebih sering muncul pada remaja.

Berdasarkan penelitian Fadhillah (2011), dari 113 partisipan remaja sebesar 33,62\% berperilaku agresi, dan jenis perilaku agresi yang banyak dilakukan adalah pencurian dengan kekerasan. Hal ini didukung juga oleh data dari LPKA (Lembaga Pembinaan Khusus Anak) Kelas II Bandung yang menunjukkan perilaku agresi remaja Bandung 22\% berupa tindak kriminal atau kejahatan (Kemenkumham, 2019). Selain itu, perilaku agresi remaja yang paling sering dilakukan adalah pencurian dengan kekerasan, pencurian kendaraan bermotor dan begal (Sindonews, 2018). Pemberitaan ini didukung juga oleh Tribunews yang memberitakan bahwa di Bandung, Senin, 7 Januari 2019 pada dini hari telah terjadi pencurian dengan kekerasan yang dilakukan oleh remaja laki-laki berusia 17 tahun kepada seorang mahasiswa perempuan (Tribunews, 2019). Selain pencurian dan kekerasan, perilaku agresi lain yang sering dilakukan oleh remaja adalah geng motor. Aksi remaja di dalam geng motor memiliki dampak negatif pada orang lain, mengganggu 
ketertiban umum, dan memicu banyak kejahatan lain, bahkan pembunuhan (Saudi, Hartini \& Bahar, 2018).

Perilaku agresi yang dilakukan oleh remaja sejalan dengan perubahan kognitif yang terjadi pada masanya, yaitu munculnya imaginary audience dan personal fable (Ormrod, 2009). Imaginary audience dan personal fable merupakan komponen utama dari egosentrisme (Santrock, 2011). Imaginary audience merupakan kecenderungan para remaja untuk berpikiran bahwa orang lain mengacu pada penampilan dirinya sehingga para remaja menganggap bahwa mereka adalah pemeran utama di depan orang banyak (Elkind, 1967). Sedangkan personal fable merupakan keyakinan yang dimiliki para remaja bahwa mereka itu unik, kebal, dan tidak ada orang lain yang dapat memahami dirinya (Elkind, 1967). Hal tersebut didukung oleh hasil penelitian Yulandari (2008) yang menunjukkan adanya hubungan positif yang signifikan antara egosentrisme dengan perilaku agresi. Berdasarkan penelitian ini, egosentrisme dapat menjadi prediktor untuk memprediksikan munculnya kecenderungan perilaku agresi (Yulandari, 2008).

Sejauh ini, penelitian terdahulu lebih banyak meneliti kaitan perilaku agresi pada remaja yang dikaitkan dengan kontrol diri remaja (Aroma \& Suminar, 2012; Fasilita, 2012), kematangan emosi remaja (Putri, 2010; Guswani \& Kawuryan, 2011; Auliya \& Auliya, 2015; Setiawati, 2015), dan konformitas sekelompok remaja (Fauziah \& Mutiah, 2015; Kartini, 2016; Rahmat, 2016; Utomo, 2013; Wilujeng, 2013). Penelitian mengenai perilaku agresi pada remaja sebagian besar berfokus pada faktor eksternal diri. Sementara masih sangat sedikit penelitian mengenai perilaku agresi yang dikaitkan dengan faktor internal diri, contohnya kognitif yang di dalamnya terdapat imaginary audience dan personal fable. Dengan demikian, hal tersebut melatarbelakangi peneliti meneliti perilaku agresi yang dikaitkan dengan imaginary audience dan personal fable atau dengan pertanyaan apakah imaginary audience dan personal fable berpengaruh terhadap kecenderungan perilaku agresi remaja?

\section{Perilaku agresi}

Perilaku agresi merupakan suatu dorongan untuk menyakiti orang lain dengan cara mengekspresikan perasaan negatif yang dimilikinya untuk mencapai suatu tujuan (Buss \& Perry, 1992). Menurut Tremblay (2000) perilaku agresi merupakan tindakan yang menyebabkan ketidaknyamanan bagi orang lain. Sedangkan jika dilihat dari sisi psikologis, perilaku agresi merupakan perilaku yang cenderung mengarah pada penyerangan kepada hal yang membuat ia merasa kecewa, menghalangi atau menghambat tercapainya tujuan yang ia miliki. (Palinoan, 2015). Ketika individu merasa terancam, individu cenderung melakukan perilaku agresi reaktif sebagai respon untuk menghindari atau melepaskan dirinya dari ancaman yang sedang diterimanya (Kardiyanto, 2014). 
Menurut Buss \& Perry (1992) perilaku agresi memiliki empat dimensi, yaitu physical aggression, verbal aggression, hostility, dan anger. Bentuk physical aggression yang biasanya dilakukan oleh remaja diantaranya adalah perkelahian antar pelajar yang sampai mengakibatkan luka parah (Suryatri, 2015). Sedangkan hal-hal yang termasuk aspek verbal agression antara lain menyebar fitnah yang berat, menghina dengan perkataan, memaki, mengancam, meledek, memberi ejekan pada nama (Buss \& Perry, 1992; Praditya, Wimbarti, dan Helmi, 1999; Handayani dan Hidayah, 2014; Sapari dan Kurniati, 2008; Palinoan, 2015; Sari, 2016). Hostility merupakan bentuk perilaku agresi yang memiliki komponen kognitif, karena berisi benci dan curiga pada orang lain, iri hati, dan merasa tidak adil di dalam kehidupan yang sedang dijalani (Suryatri, 2015). Sedangkan anger merupakan bentuk perilaku agresi yang meliputi komponen emosi atau afektif (Suryatri, 2015).

\section{Imaginary audience}

Menurut Santrock (2011) imaginary audience merupakan suatu bentuk perubahan kognitif yang terjadi pada remaja. Imaginary audience ini merupakan salah satu komponen utama dari egosentrisme remaja (Elkind, 1967). Imaginary audience merupakan sebuah kegagalan remaja dalam membedakan perspektif dirinya dari orang lain (Puscek dan Videc, 2008). Terjadinya imaginary audience ditandai dengan adanya mulai memikirkan penilaian apa yang orang lain pikirkan tentang dirinya, bagaimana penilaian orang lain terhadap penampilan dan perilaku dirinya (Lapsley, 1993).

Menurut Lapsley (1988) imaginary audience memiliki dua dimensi, yaitu object relational ideation, yakni angan-angan atau imajinasi yang berhubungan dengan keinginan remaja untuk tetap eksis di dalam kelompok sosialnya. dan self-focusing appearance, yakni remaja selalu memperhatikan detail penampilannya demi menghindari kritik-kritik dari orang lain.

\section{Personal fable}

Personal fable merupakan suatu kepercayaan atau keyakinan di dalam diri remaja jika dirinya itu unik dan serba bisa sehingga membuatnya berani mengambil resiko (Galanaki, 2012; Schwartz, Maynard \& Uzelac, 2008). Pengertian tersebut sejalan dengan pendapat Elkind (1967) yang menyebutkan Personal fable sebagai salah satu kepercayaan yang unik dan kompleks pada diri seorang remaja, misalnya seorang remaja meyakini bahwa dirinya tidak akan menghadapi kematian, tapi kematian ini akan terjadi kepada orang lain dan mereka merasa akan kebal terhadap bahaya. Sama seperti imaginary audience, personal fable pun merupakan salah satu kompenen dari egosentrisme. Personal fable yang terjadi pada masa remaja ini akan membuat remaja berpikir dan percaya bahwa dirinya unik dan istimewa (Alberts, Elkind, \& Ginsberg, 2007). Selain itu, personal fable juga membuat para remaja menjadi percaya pada perasaan dan emosi-emosi yang mereka miliki (Alberts, Elkind, \& Ginsberg, 2007) 
Menurut Lapsley (1993) personal fable memiliki tiga dimensi, yakni invulnerability, omnipotence, dan uniqueness. Invulnerability merujuk pada keyakinan remaja bahwa mereka tidak mampu disakiti atau dilukai (Dolcini, 1989). Omnipotence adalah dimana remaja melihat dirinya sebagai peribadi yang bisa berpengaruh terhadap orang banyak dan lingkungan sekitarnya (Azizah, 2016). Sedangkan uniqueness adalah dimana remaja memiliki kepercayaan bahwa tidak ada satu orang pun yang bisa mengerti akan dirinya (Azizah, 2016).

\section{METODE}

Penelitian ini menggunakan pendekatan kuantitatif dengan desain korelasional. Desain korelasional dipilih karena penelitian ini bertujuan untuk menguji pengaruh variabel imaginary audience $\left(\mathrm{X}_{1}\right)$ dan personal fable $\left(\mathrm{X}_{2}\right)$ terhadap perilaku agresi $(\mathrm{Y})$ pada remaja di Kota Bandung.

Responden dalam penelitian ini sebanyak 395 remaja dengan rentang usia 13-18 tahun yang bersekolah di SMP dan SMA di Kota Bandung. Sedangkan teknik pengambilan sampelnya itu sendiri adalah cluster random sampling.

Instrumen yang digunakan untuk mengukur imaginary audiance adalah $\mathrm{New}$ Imaginary Audience Scale (NIAS) yang memiliki reliabilitas sebesar 0,87. Instrumen yang digunakan untuk mengukur personal fable adalah New Personal Fable Scale (NPFS) yang memiliki reliabilitas sebesar 0,85. Sedangkan Instrumen yang digunakan untuk mengukur perilaku agresi adalah Buss-Perry Aggression Questionnaire (BPAQ) yang memiliki reliabilitas sebesar 0,86 .

Teknik analisa data pada penelitian ini menggunakan software SPSS dengan melakukan uji regresi berganda untuk mengetahui pengaruh dari imaginary audience dan personal fable terhadap kecenderungan perilaku agresi remaja.

\section{HASIL}

Berdasarkan hasil analisis pengaruh imaginary audience dan personal fable terhadap perilaku agresi, didapatkan nilai sig. $0,000(\mathrm{p}<0,05)$ yang berarti imaginary audience dan personal fable secara simultan berpengaruh terhadap perilaku agresi. Selain itu, didapatkan nilai $\mathrm{R}$ square sebesar 0,12 yang berarti proporsi varian dari perilaku agresi yang dijelaskan oleh imaginary audience dan personal fable adalah sebesar $12 \%$, sisanya sebesar $88 \%$ dijelaskan oleh variabel lain yang tidak terangkum dalam penelitian ini.

Hasil analisis pengaruh imaginary audience terhadap perilaku agresi menunjukkan nilai signifikansi sebesar $0,000(\mathrm{p}<0,05)$ yang berarti imaginary audience secara signifikan mempengaruhi perilaku agresi. Nilai R square yang didapatkan adalah sebesar 
,.095 yang berarti proporsi varian dari perilaku agresi yang dijelaskan oleh imaginary audience adalah sebesar $9,5 \%$.

Nilai signifikansi dari hasil analisis pengaruh personal fable terhadap perilaku agresi adalah sebesar 0,000 ( $\mathrm{p}<0,05)$. Hal tersebut menunjukkan adanya pengaruh yang signifikan personal fable terhadap perilaku agresi. Sedangkan nilai $\mathrm{R}$ square yang didapatkan adalah sebesar 0,067, yang berarti proporsi varian dari perilaku agresi yang dijelaskan oleh personal fable adalah sebesar 6,7\%.

\section{PEMBAHASAN}

Hasil penelitian ini menunjukkan bahwa imaginary audience dan personal fable secara bersama-sama dapat memengaruhi perilaku agresi. Hasil penelitian ini sejalan dengan hasil penelitian yang dilakukan oleh Bulu, Maemunah, dan Sulasmini (2019) yang menemukan bahwa imaginary audience dan personal fable yang tinggi dapat memunculkan kecenderungan remaja melakukan perilaku bullying, yang merupakan bentuk dari perilaku agresi. Hasil penelitian ini juga sejalan dengan hasil penelitian yang dilakukan Yulandari (2008) yang menunjukkan adanya hubungan positif yang signifikan antara egosentrisme dengan perilaku agresi, yang dimana egosentrisme dapat menjadi prediktor untuk memprediksikan munculnya kecenderungan perilaku agresi. Sedangkan egosentrisme itu sendiri memiliki komponen imaginary audience dan personal fable. Selain itu, hasil penelitian ini juga mendukung pernyataan Aman (2004) yang menyebutkan bahwa imaginary audience dan personal fable adalah salah satu aspek yang mempengaruhi munculnya perilaku agresi pada remaja.

Ketika imaginary audience dan personal fable muncul, remaja menjadi sangat mengutamakan kepentingan pribadi yang ditunjukkan dengan kekuasaan dan kepemilikan (Aman, 2004). Dengan adanya imaginary audience remaja merasa bahwa orang lain sangat memperhatikan dirinya dan dengan adanya personal fable membuat remaja merasa yakin bahwa dirinya mahakuasa dan dapat mempengaruhi orang lain, sehingga mereka memiliki kemungkinan melakukan perilaku agresi sebagai bentuk pertahanan diri untuk mempertahankan penilaian dan perhatian orang lain agar terus tertuju pada dirinya.

Hasil analisis yang dilakukan secara terpisah antara imaginary audience dan personal fable menunjukkan imaginary audience dan personal fable masing-masing secara signifikan mempengaruhi perilaku agresi. Imaginary audience berkontribusi sebesar $9,5 \%$ pada perilaku agresi. Sedangkan personal fable berkontribusi sebesar $6,7 \%$. Hasil penelitian ini menunjukkan bahwa perilaku agresi ini tidak hanya muncul akibat kejadiankejadian di luar individu, tetapi juga dimunculkan dari bagaimana kejadian tersebut dapat 
diterima dan diproses oleh kognitif yang mewadahi imaginary audience dan personal fable (Berkowitz, 1995; Knorth et al., 2007).

Salah satu bentuk perilaku agresi yang diakibatkan oleh imaginary audience adalah bullying (Putri, Nauli, Novayelinda, 2015; Zakiyah, Humaedi, dan Santoso, 2017). Remaja yang merasa dirinya kuat secara fisik dan memiliki rasa percaya diri yang tinggi cenderung memiliki imaginary audience yang tinggi pula, sehingga dapat menyebabkan kemungkinan terjadinya perilaku agresi. Sebagai contoh, seorang remaja yang di sekolahnya memiliki perasaan bahwa dirinya kuat dan popular di sekolah sering berkata kasar dan menyepelekan atau melecehkan sebagai salah satu bentuk perilaku agresi verbal (Astuti, 2008; Zakiyah, Humaedi, dan Santoso, 2017). Hal tersebut juga didukung oleh pernyataan Astuti (2008) yang menyatakan bahwa akibat dari imaginary audience adalah membuat remaja merasa bahwa orang lain menjadikannya pusat perhatian yang menimbulkan kecenderungan melakukan perilaku agresi dalam bentuk verbal dan fisik, sering membuat onar, sering mencari-cari kesalahan orang lain, pendendam, serta iri hati jika ada yang lebih memperhatikan orang lain dibandingkan dirinya.

Perilaku agresi lain yang diakibatkan imaginary audience adalah kelompok geng motor (Fadila, 2013). Pembentukan geng motor biasanya memiliki tujuan untuk menaikkan harga diri, memberikan para remaja suatu identitas, dan agar perilaku mereka dilihat dan diperhatikan oleh orang lain (Fadila, 2013). Selain itu, perilaku agresi juga memungkinkan dilakukan oleh remaja yang mendapat penolakan dari teman sebayanya. Remaja ini memiliki kemungkinan untuk mendebat kelompok yang menolaknya, mengganggu orang lain, cenderung berperilaku agresi, dan melakukan hal apapun agar kehadirannya dianggap dan diperhatikan oleh orang lain sebagai akibat dari imaginary audience (Usman, 2013).

Salah satu bentuk perilaku agresi yang diakibatkan oleh personal fable adalah penyerangan terhadap orang lain dalam bentuk bullying (Ramadhani, Anward, dan Rachmah, 2016). Remaja berani melakukan hal tersebut dikarenakan adanya invulnerability sebagai salah satu dimensi dari personal fable yang menyebabkan mereka merasa bahwa orang lain dapat disakiti atau akan mengalami bahaya, tetapi mereka tidak akan mengalami hal tersebut. Hal ini diperkuat oleh hasil penelitian yang dilakukan oleh Saudi, Bahar, dan Hartini (2018) yang menunjukkan bahwa terdapat pengaruh yang signifikan dari personal fable terhadap perilaku agresi yang memungkinkan nilai perilaku agresinya menjadi tinggi.

Personal fable juga memiliki dimensi omnipotence yang membuat mereka merasa dapat berkuasa atas orang lain yang lemah, karena merasa dirinya kuat mereka dengan leluasa menyakiti orang lain, dan hal tersebut merupakan perilaku agresi (Ramadhani, Anward, dan Rachmah, 2014). Hal ini sejalan dengan hasil penelitian Gracianing dan Widodo (2015) yang mengemukakan bahwa akibat dari personal fable membuat remaja 
merasa jika dirinya paling berkuasa dan merasa paling bisa memimpin di antara temantemannya, sehingga suka menghina orang lain sebagai bentuk perilaku agresi verbal.

Perilaku agresi sebagai akibat dari personal fable juga mendorong remaja memiliki kecenderungan untuk melakukan perilaku beresiko (Fathiyah dan Harahap, 2013). Perilaku beresiko yang mereka lakukan ini tidak jarang sebenarnya membahayakan diri mereka sendiri, tetapi karena kemunculan personal fable, mereka tidak peduli akan hal itu.

\section{DAFTAR PUSTAKA}

Alberts, A., Elkind, D., \& Ginsberg, S. (2007). The personal fable and risk-taking in early adolescence. Journal of Youth and Adolescence, 36(1), 71-76.

Alghaffar, R. L., \& Pratisti, W. D. (2017). Perilaku Agresif Pada Suporter Sepakbola (Doctoral dissertation, Universitas Muhammadiyah Surakarta).

Aman,T.P. (2004). Perbedaan Agresivitas Pada Anggota Pencak Silat THS-THM Ditinjau Dari Tingkat Pratama Dan Tingkat Tamtama. Skripsi (tidak diterbitkan). Semarang: Fakultas Psikologi Universitas Katolik Soegijapranata

Aroma, I. S., \& Suminar, D. R. (2012). Hubungan antara tingkat kontrol diri dengan kecenderungan perilaku kenakalan remaja. Jurnal Psikologi Pendidikan dan Perkembangan, 1(2), 1-6.

Astuti K, Walgito PPDB. Model Kognitif Sosial Perilaku Merokok pada Remaja [Social Cognitive Model of Adolescent Smoking Behavior]. [Doctoral dissertation]. Yogyakarta: Universitas Gadjah Mada; 2010.

Auliya, M., \& Auliya, M. (2015). Hubungan Kontrol Diri Dengan Perilaku Agresi Pada Siswa Sma Negeri 1 Padangan Bojonegoro. Character: Jurnal Penelitian Psikologi., 2 (3).

Azizah, N. (2016). Korelasi Personal Fable Terhadap Kompetensi Sosial Remaja.

Baron, R. A., dan Byrne, D. 2003. Psikologi Sosial Jilid 2. Edisi 10. Penerjemah: Ratna Juwita. Jakarta: Penerbit Erlanggga.

Batubara, J. R. (2010). Adolescent development (perkembangan remaja). Sari Pediatri, 12(1), 21-9.

Berkowitz, L. (1995). Agresi: Sebab dan Akibatnya. Terjemahan. Jakarta: Pustaka Binaman Pressindo.

Bulu, Y., Maemunah, N., \& Sulasmini, S. (2019). Faktor-faktor yang mempengaruhi perilaku bullying pada remaja awal. Nursing News: Jurnal Ilmiah Keperawatan, 4(1).

Buss, A. H., \& Perry, M. (1992). The aggression questionnaire. Journal of personality and social psychology, 63(3), 452. 
Diana, R. R., Retnowati, S., Psikologi, F., \& Mada, U. G. (2009). Komunikasi remajaorang tua dan agresivitas pelajar. Jurnal Psikologi, 2(2), 1-6.

Dolcini, M. M., Cohn, L. D., Adler, N. E., Millstein, S. G., Irwin Jr, C. E., Kegeles, S. M., \& Stone, G. C. (1989). Adolescent egocentrism and feelings of invulnerability: Are they related?. The Journal of Early Adolescence, 9(4), 409-418.

Elida Prayitno dan Erlamsyah, Psikologi Perkembangan Remaja (Padang: UNP Press, 2002).

Elkind, D. (1967). Egocentrism in Adolescence. Child development, 1025-1034.

Fadhillah, Sunni. (2011). Hubungan Antara Kemampuan Pengelolaan Emosi dengan Perilaku Agresif Siswa. Skripsi. Universitas Pendidikan Indonesia. Bandung: Tidak diterbitkan.

Fadila, R. (2013). Hubungan identitas sosial dengan perilaku agresif pada geng motor. Psikologia: Jurnal Pemikiran dan Penelitian Psikologi, 8(2).

Fasilita, D. A. (2012). Kontrol Diri Terhadap Perilaku Agresif Ditinjau Dari Usia Satpol Pp Kota Semarang. Journal of Social and Industrial Psychology, 1(2).

Fauziah, S., \& Mutiah, D. (2015). Pengaruh Trait Kepribadian Big Five dan Konformitas Teman Sebaya Terhadap Agresivitas Anak Punk di Jabodetabek. Raheema, 2(2).

Feshbach,N.D.(1969).Sex differences in children's modes of aggressive responses toward outsiders. Merrill-Palmer Quarterly, 15, 249 - 258.

Galanaki, E. P. (2012). The Imaginary Audience and The Personal Fable: A test of Elkind's Theory of Adolescent Egocentrism. Psychology, 3(6), 457.

Gracianing, G. Y., \& Widodo, B. (2015). Pengaruh Pola Asuh Permisif Dan Kompetensi Sosial Remaja Terhadap Perilaku Egosentrisme. Educatio Vitae, 2(2).

Guswani, A. M., \& Kawuryan, F. (2011). Perilaku agresi pada mahasiswa ditinjau dari kematangan emosi. Jurnal Psikologi UMK: PITUTUR, 1(2), 86-92.

Handayani, A. T. (2018). Hubungan Body Image Dan Imaginary Audience Dengan Kepercayaan Diri Pada Remaja Di SMA Panca Budi Medan. Jurnal Penelitian Pendidikan Sosial Humaniora, 3(1), 319-324.

Kartini, H. (2016). Hubungan antara Konformitas Teman Sebaya dan Intensitas Bermain Game Online dengan Intensi Berperilaku Agresif pada Siswa SMA Katolik WR Soepratman Samarinda. Jurnal Psikologi.

Kementrian Hukum dan HAM Republik Indonesia. Kantor Wilayah Jawa Barat. [online]. Tersedia: https://jabar.kemenkumham.go.id/

Knorth, E. J., Klomp, M., Van der Bergh, P. M., \& Noom, M. J. (2007). Aggressive Adolescents in Residential Care: A Selective Review of Treatment Requirements and Models. Adolescence, 42 (167), 461-485.

Krahe, B. (2005). Buku Panduan Psikologi Sosial: Perilaku Agresif. Yogyakarta: PT Pustaka Belajar. 
Lapsley, D. K., \& Rice, K. (1988). The "New Look" at The Imaginary Audience and Personal Fable: Toward a General Model of Adolescent Ego Development. in Self, Ego, and Identity (Pp. 109-129). Springer, New York, NY.

Monks, F.J. (2002) Psikologi Perkembangan: Pengantar Dalam Berbagai Bagiannya. Cet. 14.: Yogyakarta: Gajah Mada University Press.

Ormrod, Ellis, Jeanne. 2009. Psikologi Pendidikan Membantu siswa Tumbuh dan Berkembang. Jakarta: Erlangga.

Palinoan, Erick Lolang. (2015). Pengaruh Konformitas dan Agresivitas pada Kelompok Geng Motor di Samarinda. eJournal Psikologi. Vol. 4(1), hlm 79-94.

Piaget, J., \& Inhelder, B. (1956). The child's conception of space. London: Routledge \& Kegan Paul.

Praditya, L. Dion, Wimbarti, Supra, dan Helmi, Avin Fadilla. (1999). Pengaruh Tayangan Kekerasan yang Nyata Terhadap Agresivitas. Jurnal Psikologi. (1), hlm 51-63.

Pratiwi, N. L., \& Basuki, H. (2011). Hubungan Karakteristik Remaja Terkait Risiko Penularan Hiv-aids Dan Perilaku Seks Tidak Aman Diindonesia. Buletin Penelitian Sistem Kesehatan, 14(4).

Putri, F. A. (2010). Hubungan kematangan emosi dengan agresivitas remaja akhir lakilaki.

Rahmat, H. I. (2016). Hubungan antara konformitas dengan kecenderungan perilaku agresif pada suporter sepak bola Persib di Kabupaten Bekasi (Doctoral dissertation, Universitas Bhayangkara Jakarta Raya).

Ramadhani, H. R., Anward, H. H., \& Rachmah, D. N. (2016). Peranan Lima Besar Kepribadian terhadap Kecenderungan Buli pada Remaja. Jurnal Ecopsy, 1(3).

Santoso, M. \& Satiadarma, M.P. 2005. Hubungan antara Rasa Percaya Diri dan Agresivitas pada Atlet Bola Basket. Jurnal Phronesis, 1, 51- 64.

Santrock, J. W. (2011). Adolescence: Perkembangan Remaja. Edisi Keenam. Jakarta: Erlangga.

Sapari, Agus dan Ni Made Taganing Kurniati. (2008). Gambaran Agresivitas Aparat Kepolisian yang Menangani Demonstrasi. Jurnal Psikologi. Vol. 1(2), hlm 129-135.

Saudi, A. N. A., Hartini, N., \& Bahar, B. (2018). Teenagers' motorcycle gang community aggression from the Personal Fable and risk-taking behavior perspective. Psychology research and behavior management, 11, 305.

Sentana, M. A., \& Kumala, I. D. (2017). Agresivitas dan Kontrol Diri pada Remaja di Banda Aceh. Jurnal Sains Psikologi, 6(2), 51-55.

Setiawati, R. (2015). Hubungan Antara Kecerdasan Emosi Dengan Perilaku Agresi Remaja (Doctoral dissertation, Universitas Muhammadiyah Surakarta). 
Sumintono, B dan Widhiarso, W. (2013). Aplikasi Model Rasch untuk Penelitian Sosial. Cmahi: Trim Komunikata Publishng House.

Usman, I. (2013). Perilaku Bullying Ditinjau dari Peran Kelompok Teman Sebaya dan Iklim Sekolah Pada Siswa SMA di Kota Gorontalo. Gorontalo: Universitas Negeri Gorontalo.

Schwartz, P. D., Maynard, A. M., \& Uzelac, S. M. (2008). Adolescent Egocentrism: A Contemporary View. Adolescence, 43(171), 441.

Suryatri, I. (2015). Hubungan Kontrol Diri Dengan Perilakuagresi Remaja (Doctoral dissertation, Universitas Islam Negeri Sultan Syarif Kasim Riau).Tremblay, Richard E. (2000). The Development of Aggressive Behavior During Childhood: What We Have Learned in The Past Century? International Journal of Behavioral Development. Vol. 24(2), hlm 129-141.

Utomo, H. (2013). Hubungan antara frustasi dan konformitas dengan perilaku agresi pada suporter Bonek Persebaya. Character: Jurnal Penelitian Psikologi., 1(2).

Vogt, W. P., \& Johnson, B. (2011). Dictionary of statistics \& methodology: A nontechnical guide for the social sciences. Sage.

Wilujeng, P. (2013). Pengaruh Konformitas Pada Geng Remaja Terhadap Perilaku Agresi Di Smk Pgri 7 Surabaya. Character: Jurnal Penelitian Psikologi., 1(2).

Yulandari, S. (2008). Hubungan Antara Egosentrisme dan Kecenderungan Mencari Sensasi Dengan Perilaku Agresi Pada Remaja (Doctoral dissertation, Universitas Muhammadiyah Surakarta).

Zakiyah, E. Z., Humaedi, S., \& Santoso, M. B. (2017). Faktor yang memengaruhi remaja dalam melakukan bullying. Prosiding Penelitian dan Pengabdian kepada Masyarakat, 4(2). 